\title{
ОРГАНИЗАЦИЯ ПРОЕКТНОГО СЕМИНАРА В ПРАКТИКЕ ВЗАИМОДЕЙСТВИЯ ВУЗА И ШКОЛЫ: ОБРАЗОВАТЕЛЬНОЕ СОДЕРЖАНИЕ СОВМЕСТНОЙ ДЕЯТЕЛЬНОСТИ
}

\author{
Е. Н. Ковалевская ${ }^{1}$, А. В. Курьянович ${ }^{1}$, А. И. Дукмас ${ }^{2}$ \\ ${ }^{1}$ Томский государственный педагогический университет \\ ${ }^{2}$ МАОУ СОШ № 14 м. А.Ф. Лебедева г. Томска
}

Исследование посвящено концептуализации, экспертизе содержания деятельности в сетевом образовательном проекте вуза и школы «Формирование профессиональной культуры педагогов в современной образовательной ситуации: взаимодействие вуза и школы в условиях перехода на новые федеральные государственные образовательные стандарты для среднего (общего) и высшего профессионального образования». Представлена реконструкция проведения проектного семинара «Использование личностно ориентированных технологий для развития текстовой деятельности обучающихся в процессе их подготовки к итоговой аттестации по русскому языку». Организаторами, участниками семинара (бакалаврами, магистрантами историко-филологического факультета Томского государственного педагогического университета, обучающимися 11-го класса средней школы, учителями-филологами г. Томска) осмыслен опыт развития текстовой деятельности с использованием педагогического ресурса личностно ориентированных технологий. Показано, как в пространстве семинара проявляется разное образовательное содержание совместной деятельности. Для формирования знаниевого ресурса обучающихся - нормативно-фукнкциональное, реализующееся на уроке-задании. Обеспечение деятельностного компонента развития текстовой деятельности участников семинара происходит за счет использования ценностно-соподчинительных связей, возникающих в контексте урока-проблематизации. Смысловая составляющая образовательного содержания совместной деятельности формируется в диалоге, в контексте взаимодополнительных связей. Диалог в этом контексте выступает катализатором, запускающим развитие текстовой деятельности, которое происходит за счет использования других форм совместной деятельности: нормативной и проектной. Изменение содержания образования происходит в логике сюжета смыслодеятельности: появления, развития и оформления в культурную норму смыслов участников. Методическим инструментом, позволяющим использовать в совместной деятельности разные формы ее организации, может являться технология развития критического мышления через чтение и письмо. Использование таких ее приемов, как «синквейн», «направляющий текст», обеспечивает развитие компетенций текстовой деятельности, необходимых обучающимся для написания сочинений в соответствии с требованиями итоговой аттестации по русскому языку. Содержание совместной деятельности, спроектированной и организованной таким образом, позволяет реализовывать компетентностный подход в образовании. Формируется проектно-деятельностный ресурс участников семинара, представляющих вуз, осуществляется развитие универсальных учебных действий обучающихся школы.

Ключевые слова: сетевой проект, образовательное проектирование, совместная деятельность, диалог, смыслодеятельность. 
Реализация целей, требований новых федеральных государственных образовательных стандартов для высшего и среднего образования $[1,2]$ привела к усилению активности во взаимодействии этих сфер образования. Наш сетевой образовательный проект возник как ответ на требование ситуации - обеспечить реализацию установок компетентностного подхода в обучении. Создавая свой проект, мы исходили из того, что универсальные учебные действия (УУД), на формирование которых нацелен федеральный государственный образовательный стандарт среднего общего образования (ФГОС) школы, по своему когнитивному, деятельностному и смысловому содержанию совпадают с образовательным наполнением содержания компетенций различного характера (общих, профессиональных), которые формируются в логике ФГОС ВО $[3,4]$. Такое видение, понимание социально-образовательного момента привели к организации стратегии и тактики экспериментальной работы в рамках взаимодействия Томского государственного педагогического университета (ТГПУ) и МАОУ СОШ № 14 имени А. Ф. Лебедева г. Томска.

Мы рассматриваем свою деятельность как инновационную, требующую личностной профессиональной инициативы участников проекта. Проявленность, успешность подобной деятельности фиксируется в формировании особой образовательной реальности, т. е. организации прецедентов практики взаимодействия вуза и школы, в рамках которых происходит развитие УУД обучающихся и формирование компетентностного ресурса бакалавров и магистрантов вуза. В качестве таких прецедентов, активно работающих на решение актуальных проблем образования, в нашем взаимодействии явились сетевой образовательный проект (СОП) «Дебаты», муниципальная конференция «Наши духовные ценности» и научно-практическая конференция «Наука и образование». В них участвуют обучающиеся, педагоги школы, студенты, магистранты и аспиранты ТГПУ. Накоплен богатый опыт использования различных форм взаимодействия участников СОП, который требует осмысления на новом концептуальном уровне [5].

Определяющей характеристикой инновационной деятельности является возникновение новых проблем, смыслов, работа с которыми требует их понимания в новом контексте. Наступил момент исследовательского сопровождения СОП, и он связан с управлением, развитием содержания деятельности в нем [6].

Необходимость такого сопровождения обусловлена социальным заказом: реализацией требований новых образовательных стандартов.

Цель исследования - проявив образовательное содержание совместной деятельности (СД) в рамках проектного семинара, представить особенности ее организации.

Задачи:

1) описать образовательные прецеденты СД в рамках проектного семинара;

2) проявить эмпирические признаки образовательного содержания СД;

3) представить модель образовательного содержания СД на проектном семинаре в рамках взаимодействия вуза и школы.

Авторы, являющиеся непосредственными создателями (проектировщиками, организаторами) прецедентов инновационной образовательной реальности, возникающих в СОП, ориентируются на стратегию антропологического подхода [7]. Исследовательская тактика его реализации в статье представлена методологией гуманитарного исследования [8], предполагающей реконструкцию инновационного опыта в форме описания образовательных прецедентов. При этом происходит выявление эмпирических признаков проявления образовательного содержания СД, установление зависимостей между ними и формирование модели образовательного содержания СД в проектном семинаре. 


\section{Содержание исследования}

Теоретические основы. Реконструкция опыта проведения проектного семинара строится в ориентире на смысловые локусы, которые определяют содержание построения нашей антропопрактики. Речь идет об ориентации на концепцию образовательного проектирования, рассматривающую деятельность участников семинара как развитие их субъектности [9].

Средой, позволяющей достигать целей образовательного проектирования, выступает СД. Взаимно дополнительные связи участников СД формируют ее различное образовательное содержание. В авторитарном взаимодействии возникает закрытый тип образовательного действия, происходит формирование знаний, умений и навыков обучающихся. В лидерской модели СД порождаются ценностно-соподчинительные связи, происходит освоение способов деятельности участниками. В третьем типе СД развивается взаимно дополнительные, партнерские связи в формате диалоговой модели [10].

Образовательное содержание СД обнаруживается в появлении в ее пространстве субъектно-личностной составляющей в смыслодеятельности: актуализации, развитии, оформлении смыслов участников. Движение смыслов происходит за счет использования образовательных возможностей технологии развития критического мышления через чтение и письмо (РКМЧП) в СД.

Описание прецедентов проявления образовательного содержания совместной деятельности в рамках проектного семинара «Развитие текстовой деятельности обучающихся с использованием личностно ориентированных технологий в процессе их подготовки к итоговой аттестации по русскому языку»:

Ситуация 1. Погружение в контекст. Участникам семинара (обучающимся школы, бакалаврам, магистрантам ТГПУ, педагогам-филологам г. Томска) объясняются условия их участия в образовательном событии. В экспресс-опросе после выявления трудностей в обозначенной сфере деятельности (создание текстов в формате итоговой аттестации) предлагалось осмыслить образовательный ресурс технологии РКМЧП. Спикер, представляющий информацию, подчеркнул, что важны будут приемы «синквейн», «направляющий текст», которые позволяют организовать развитие текстовой деятельности [11]. Было артикулировано содержание гипотезы, в рамках которой участники проекта становились исполнителями, разработчиками, экспертами собственной проектной деятельности. В качестве экспертизы педагогам школы предлагалось освидетельствовать идею о том, что развитие текстовой деятельности может происходить в логике смыслодеятельности (смыслы, возникающие в диалоге, развиваются с помощью пробных проектных действий и оформляются в текст - культурную форму). Формой, запускающей совместную деятельность, является диалог; затем движение смыслов осуществляется за счет ресурсов технологии РКЧМП.

Аналитический комментарий. В пространстве семинара использовались педагогические возможности диалога. Моменты смыслодеятельности присутствовали в совместном определении целей работы, распределении функций участников на договорных, партнерских основаниях.

Ситуация 2. Встреча с А. П. Чеховым: сочинение в формате ЕГЭ. Организовывалось погружение в рассказ А. П. Чехова «Орден», который представлял собой вариант задания № 27, предложенного в утвержденных контрольно-измерительных материалах. Текст потенциально создавал возможность для активной смыслодеятельности. Пустяков - герой, поведенчески мобильный, ловко пользуется принципами морали.

Актуализация смыслов случилась после предложения учителя определить проблемы текста. Первичное дискурсивное смысловое пространство выглядело так: обозначились 
понятия «игра», «обман», «честолюбие», «пошлость», «ценности». Участники семинара были готовы философствовать по поводу случившегося, оценивать, осуждать главного героя рассказа.

Педагог предлагал, выбрав любую из позиций, составить с ней синквейн, т. е. концептуализировать свое видение момента, одновременно представив в тексте-концепте собственное выполнение требований ЕГЭ (критерии К1-К5). Через 10 мин произошло обогащение первичного концептуального дискурса. Примеры синквейнов:

Игра

хитрая, эффективная

заставляет, включает, обнаруживает

человек выбирает свою самореализацию азарт

(В. Блинов, обучающийся 11 «А» класса)
Обман

спонтанный, захватывающий

возникает, утверждает, показывает

человек познает себя сам

удовлетворенность

(Т. Ведрова, ст. 4-го курса ИФФ ТГПУ)

Процедура защиты текстов-концептов проявила нравственно-идеологическую полифонию в понимании проблематики рассказа писателя. Философское приятие ситуации («человек должен сам выбирать свои иенностные ориентиры, справляться со своим выбором», Л. Гурбанова, 11-й класс) соседствовала с гневным осуждением («герой-обманщик по своей природе... он раб ложных иенностей, боится своей сути», С. Мезенцева, студентка ТГПУ).

Аналитический комментарий. В образовательном содержании СД присутствовали моменты актуализации, развития смыслов участников. Синквейн, выступающий в качестве пробного действия, позволил оформить текст в нормативное я-пространство, создал базу для дальнейшего написания сочинения. Диалог в качестве катализатора смыслодеятельности выполнил свою организующую функцию: ресурс РКМЧП дал возможность обучающимся в дальнейшем написать сочинение в соответствии с требованиями ЕГЭ.

Ситуация 3. Размышляем о совести. Сочинение в формате ОГЭ. Участники семинара знакомятся с текстом задания 15.3, взятом из утвержденных контрольно-измерительных материалов. Это грустная история о том, как один из учеников, Коля Бабушкин, своеобразный изгой в классе, подумал, что книга ему в подарок на день рождения. Владелец книги, Санька, грубо просит вернуть ее назад. После этого, став взрослым, герой понимает, что совершил плохой поступок, разрушил то, что он называет «домом человеческой веры». Но ничего уже сделать не может, так как Колька погиб на войне в Афганистане.

Этот текст предлагалось осмыслить в фокусе задания ОГЭ: поразмышлять о совести. Появились тексты-версии, возникло первичное дискуссионное пространство: «Совесть это внутренний контролер человека...», «совесть - это нравственный ориентир, регулятор в нашей жизни».

Вновь, как и в предыдущей ситуации, в проектирование включается ресурс РКМЧП: предлагалось, используя прием «направляющий текст», обогатить первичное представление о понятии «совесть». Возник вторичный дискурс: идеологические тексты-концепты («когда ты поступаешь подло, безнравственно, включается внутренний голос, ты понимаешь, как низко ты упал...» С. Писарова, студентка ТГПУ; «Благородныле поступки мы совершаем потому, что внутри каждого человека живут идеальные представления о том, каким он должен быть, об этом говорит его совесть», А. Вишнякова, магистрант ТГПУ).

\section{Аналитический комментарий}

Защита текстов, созданных с помощью методики РКМЧП, позволила зафиксировать организующую роль диалога в развитии текстодеятельности. Оно происходило с помощью 
проектного приема, позволившего оформить текст сочинения в культурную норму в соответствии с требованиями к сочинению в формате ОГЭ.

Ситуация 4. Экспертиза образовательного содержания СД: проявленность субъектных позиций участников семинара. Педагогам-филологам, участникам семинара, предлагалось, заняв позицию экспертов, совершить пробные действия и в исследовательской ситуации проявить образовательное содержание СД, которую они наблюдали [12]. Необходимо было воспользоваться тестом, разработанным Г. Н. Прозументовой, «Диагностика функционально-смыслового содержания СД и позиции педагога». Тест содержит характеристики различных моделей СД: авторитарной, лидерской, партнерской [13]. Возникает возможность:

- проявить их наличие в СД;

- показать преобладание какой-либо из трех моделей;

- охарактеризовать позицию педагога в этом сюжете действия;

- обозначить проблемы организации СД в рамках семинара.

Тест сконструирован таким образом, что эксперт обнаруживает не только присутствие разного вида связей и форм деятельности, но и фиксирует качество этого присутствия. Приведем фрагмент теста.

\begin{tabular}{|c|c|c|c|c|}
\hline \multirow{2}{*}{ Показатель } & \multicolumn{2}{|c|}{ Проявленность в СД } & \multicolumn{2}{|c|}{ Осуществленность в СД } \\
\cline { 2 - 5 } & есть & нет & успешно & неуспешно \\
\hline 2. Трудности, проблемы, воз- & & & & \\
никающие в СД \\
$\begin{array}{c}\text { - вовлечение всех и каждого } \\
\text { участников СД в выполнение об- } \\
\text { щих заданий, единых требований } \\
\text { и норм деятельности }\end{array}$
\end{tabular}

Эксперты оценивали образовательное содержание СД двух прецедентов в заданной логике, делая акцент на двух моментах:

- обнаружении феномена присутствия трех типов образовательного содержания СД: нормативного, проектного и диалогового;

- определении частоты использования обозначенных действий (часто/не часто/совсем не присутствовали). Эта позиция была важна для организаторов в точки зрения технологической грамотности: выполнения ими того или иного действия.

Результаты экспертизы. Ответы респондентов позволили обнаружить:

- три вида взаимно дополнительных связей, реализованных в ходе семинара: нормативно-функциональных (31 \%), ценностно-соподчинительных (28 \%); смыслообразующих (41\%). Для нас это означало, что проявилась идея о разных вариантах образовательного содержания в СД: формирующем знание, развивающем способы деятельности, оформляющем способы деятельности и развивающем смыслообразование;

- присутствие в практике организации семинара трех моделей СД: авторитарной, лидерской, партнерской.

Данные, приведенные выше, дали основание говорить о продуктивности смыслообразующей СД, организованной в рамках эксперимента.

\section{Аналитическое обобщение и выводы}

1. Организация проектного семинара в практике взаимодействия вуза и школы может осуществлять в рамках гуманитарного и антропологического подходов к проектированию. Это предполагает вовлечение субъектов образовательной практики в ее построение, развитие 
и осмысление. В этом контексте СД является объектом и предметом организационных усилий устроителей семинара.

2. Образовательное содержание СД в этой логике создается в парадигме компетентностного подхода, который предполагает формирование у обучающихся знаниевого, деятельностного, мотивационно-смыслового ресурсов. В контексте новых образовательных стандартов эта позиция реализуется в развитии УУД у обучающихся средней общеобразовательной школы, компетенций различного содержания у студентов и магистрантов ИФФ ТГПУ.

3. В рамках проектного семинара формирование деятельностно-компетентностного ресурса обучающихся происходит в процессе создания и освоения ими различных взаимно дополнительных связей (функционально-нормативных, ценностно-соподчинительных, смыслообразующих), которым соответствуют формы СД: авторитарная, лидерская, партнерская. СД, выстроенная на этих основаниях, может быть успешной, реализующей установки компетентностного подхода, если:

- проектировать образовательную реальность в сюжете смыслодеятельности (актуализация, разворачивание и оформление смыслов);

- использовать диалог в качестве базовой формы СД «запускающий проект»;

- рассматривать развитие образования в СД как обогащение смыслов ее участников.

Сказанное можно представить в виде схемы (рисунок).

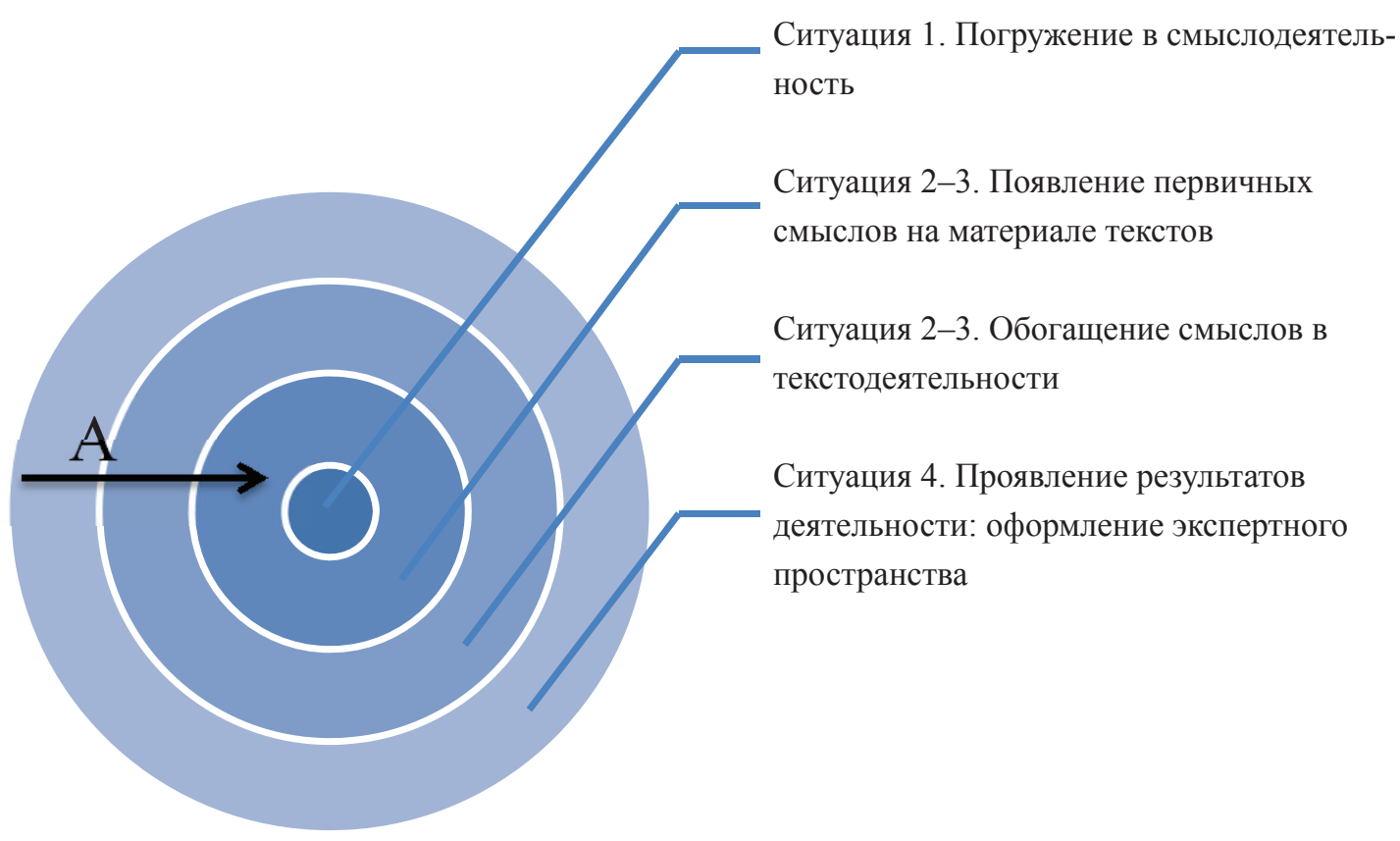

Схема развития образовательного содержания СД в рамках проектного семинара: А - пространство развития образовательного содержания СД в рамках проектного семинара во взаимодействии вуза и школы

\section{Список литературы}

1. Федеральный государственный образовательный стандарт высшего образования (утв. приказом Министерства образования и науки РФ от 09.02.2016 № 91). URL: http://fgosvo.ru/uploadfiles/fgosvob/440305.pdf (дата обращения: 29.09.2019).

2. Федеральный государственный образовательный стандарт среднего (полного) общего образования / Министерство образования и науки Российской Федерации. М.: Просвещение, 2013. 63 с.

3. Хуторской А. В. Педагогическая инноватика: методология, теория, практика. М.: Изд-во УНЦ ДО, 2005. 222 с. 
4. Бондаревская Е. В., Кульневич С. В. Парадигмальный подход к разработке содержания ключевых педагогических компетенций // Педагогика. 2004. № 1. С. 23-31.

5. Ковалевская Е. Н., Курьянович А. В., Гайворонская А. В., Дукмас А. И. Вуз - школа: содержание, формы, концептуальные аспекты взаимодействия участников сетевого образовательного проекта // Вестн. Томского гос. пед. ун-та (TSPU Bulletin). 2019. Вып. 2 (199). C. 90-97. DOI 10.23951/1609-624X-2019-2-90-97.

6. Прозументова Г. Н. Образовательные инновации: феномен «личного присутствия» и потенциал управления (опыт гуманитарного исследования). Томск: Изд-во Том. ун-та, 2016. 412 с. (Серия «Университет - учителю»).

7. Слободчиков В. И., Исаев Е. И. Основы психологической антропологии. Психология человека: введение в психологию субъективности: учеб. пособие. М.: Школа-Пресс, 1995. 384 с.

8. Прозументова Г. Н. Стратегия и программа гуманитарного исследования образовательных инноваций // Переход к открытому образовательному пространству. Ч. 1: Феноменология образовательных инноваций / под ред. Г. Н. Прозументовой. Томск: Изд-во Том. ун-та, 2005. С. 15-105.

9. Малкова И. Ю. Концепция и практика организации образовательного проектирования в инновационной школе: дис. ... д-ра пед. наук. Томск, 2008. 286 с.

10. Школа совместной деятельности: концепция, проекты, практика развития / под ред. Г. Н. Прозументовой. Томск, 1997. Кн. 1. С. 12-19.

11. Полат Е. С. Новые педагогические и инфоормационные технологии в системе образования. М., 2002. Ч. 1, гл. 2; ч. 2 , гл. 3.

12. Мацкевич В. В. Исследование действием // Вопросы методологии. 2002. № 1-2. С. 109-120.

13. Первый шаг: от авторитаризма к авторству: учеб.-метод. материалы к образовательной программе «Педагог - участник и организатор совместной деятельности». Томск: Изд-во ТГПУ, 2001. С. 10-14.

Ковалевская Елена Николаевна, кандидат педагогических наук, доцент, Томский государственный педагогический университет (ул. Киевская, 60, Томск, Россия, 634061). E-mail: iff2001@yandex.ru

Курьянович Анна Владимировна, доктор филологических наук, профессор, заведующая кафедрой, Томский государственный педагогический университет (ул. Киевская, 60, Томск, Россия, 634061). E-mail: anna.kurjanowitch@yandex.ru

Дукмас Анастасия Игоревна, учитель русского языка и литературы, руководитель МО русского языка и литературы, МАОУ СОШ № 14 им. А. Ф. Лебедева (ул. Карла Ильмера, 11, Томск, Россия, 634057). E-mail: nastya261092@yandex.ru

DOI 10.23951/2307-6127-2020-1-137-145

\title{
ORGANIZATION OF PROJECT SEMINAR IN THE PRACTICE OF INTERACTION BETWEEN UNIVERSITY AND SCHOOL: EDUCATIONAL CONTENT OF JOINT ACTIVITIES
}

\author{
E. N. Kovalevskaya ${ }^{1}$, A. V. Kuryanovich ${ }^{1}$, A. I. Dukmas ${ }^{2}$ \\ ${ }^{1}$ Tomsk State Pedagogical University, Tomsk, Russian Federation \\ ${ }^{2}$ Secondary school № 14 named after A. F. Lebedeva, Tomsk, Russian Federation
}

The study is devoted to conceptualization, examination of the content of activities in the university's and school's network educational project "Formation of the professional culture of teachers in the modern educational situation: the interaction of university and school in the context of the transition to the new Federal state educational standards for secondary (general) and higher professional education". The article presents the reconstruction of the project seminar "The use of personality-oriented technologies for the development of student's text 
activities of in the process of their preparation for the final certification in the Russian language in the format of the requirements of the Unified state exam and the General state exam". The organizers, participants of the seminar (bachelors, undergraduates of Faculty of history and philology of Tomsk State Pedagogical University, students of the 11th grade of high school, teachers and philologists of Tomsk) comprehend the experience of developing textual activity using a pedagogical resource of personality-oriented technologies. The article demonstrates how in the space of the seminar the different educational content of the joint action is manifested. For the formation of the knowledge resource of students - normativefunctional, implemented in the task lesson. The activity component of the development of a textual activity of the seminar participants is ensured through the use of value-subordinate relations arising in the context of the lesson-problematization. The semantic component of the educational content of joint activities is formed in the dialogue, in the context of mutually complementary relationships. Dialogue in this context acts as a catalyst, triggering the development of textual activity, which occurs through the use of other forms of joint activities: normative and project. Changes in the content of education occur in the logic of the plot of meaningful activity: the appearance, development, and registration of the meanings of participants in the cultural norm. A methodological tool that allows using different forms of its organization in joint activities can be the technology of the development of critical thinking through writing. The use of such techniques as "Cinquain", "Directing text" ensures the development of textual competencies necessary for students to write essays in accordance with the requirements of the Unified state exam and the General state exam. The content of joint activities designed and organized in such a way allows to implement the competence approach in education. The competence resource of the project participants representing the University is formed, the development of students' universal learning actions are carried out.

Keywords: network project, educational design, joint activities, dialogue, meaningful activities.

\section{References}

1. Federal'nyy gosudarstvennyy obrazovatel'nyy standart vysshego obrazovaniya (utv. prikazom Ministerstva obrazovaniya nauki RF ot 09.02.2016 no. 91) [Federal State Educational Standard of Higher Education (approved by order of the Ministry of Education and Science of the Russian Federation from February 9, 2016 no. 91)] (in Russian). URL: http://fgosvo.ru/uploadfiles/ fgosvob/440305.pdf (accessed 29 September 2019).

2. Federal'nyy gosudarstvennyy obrazovatel'nyy standart srednego (polnogo) obshhego obrazovaniya. Ministerstvo obrazovaniya i nauki Rossiyskoy Federatsii [Federal State Educational Standard of Secondary (Full) General Education. Ministry of Education and Science of the Russian Federation]. Moscow, Prosveshcheniye Publ., 2013. 63 p. (in Russian).

3. Khutorskoy A. V. Pedagogicheskaya innovatika: metodologiya, teoriya, praktika [Pedagogical innovation: methodology, theory, practice]. Moscow, Educational and scientific center of pre-university education Publ., 2005. 222 p. (in Russian).

4. Bondarevskaya E. V., Kul'nevich S. V. Paradigmal'nyy podkhod k razrabotke soderzhaniya klyuchevykh pedagogicheskikh kompetentsiy [A paradigmatic approach to developing the content of key pedagogical competencies]. Pedagogika, 2004, no. 1, pp. 23-31 (in Russian).

5. Kovalevskaya E. N., Kur'yanovich A. V., Gayvoronskaya A. V., Dukmas A. I. Vuz - shkola: soderzhaniye, formy, kontseptual'nyye aspekty vzaimodeystviya uchastnikov setevogo obrazovatel'nogo proyekta [University - school: content, forms, conceptual aspects of the interaction of participants in a network educational project]. Vestnik Tomskogo gosudarstvennogo pedagogicheskogo universiteta - Bulletin of TSPU, 2019, vol. 2 (199), pp. 90-97. DOI 10.23951/1609-624X-2019-2-90-97 (in Russian).

6. Prozumentova G. N. Obrazovatel'nyye innovatsii: fenomen "lichnogo prisutstviya" i potentsial upravleniya (opyt gumanitarnogo issledovaniya) [Educational innovations: the phenomenon of "personal presence" and management potential (humanitarian research experience)]. Tomsk, TSU Publ., 2016. 412 p. (in Russian).

7. Slobodchikov V. I., Isayev E. I. Osnovy psikhologicheskoy antropologii. Psikhologiya cheloveka: vvedeniye v psikhologiyu sub"yektivnosti: ucheb. posobiye [Fundamentals of psychological anthropology. Human psychology: introduction to psychology subjectivity: educational material]. Moscow, Shkola-Press Publ., 1995. 384 p. (in Russian). 
8. Prozumentova G. N. Strategiya i programma gumanitarnogo issledovaniya obrazovatel'nykh innovatsiy [The strategy and program of humanitarian studies of educational innovations]. Perekhod $k$ otkrytomu obrazovatel'nomu prostranstvu. Ch. 1: Fenomenologiya obrazovatel'nykh innovatsiy [The transition to the Open educational space. Part 1: Phenomenology of educational innovations]. Ed. by G. N. Prozumentova. Tomsk, Publishing House of Tomsk University Publ., 2005. Pp. 15-105 (in Russian).

9. Malkova I. Yu. Kontseptsiya i praktika organizatsii obrazovatel'nogo proyektirovaniya v innovatsionnoy shkole. Dis. dokt. ped. nauk [The concept and practice of organization of educational project in an innovative school. Diss. doct. of ped. sci.]. Tomsk, 2008. 286 p. (in Russian).

10. Shkola sovmestnoy deyatel'nosti: kontseptsiya, proyekty, praktika razvitiya [School of joint activity: concept, projects, practice development]. Ed. by G. N. Prozumentova. Tomsk, 1997. Book 1. Pp. 12-19 (in Russian).

11. Polat E. S. Novyye pedagogicheskiye i informatsionnyye tekhnologii v sisteme obrazovaniya [New pedagogical and information technologies in the education system]. Moscow, 2002. P. 1, ch. 2; p. 2, ch. 3 (in Russian).

12. Matskevich V. V. Issledovaniye deystviyem [Action Research]. Voprosy metodologii, 2002, no. 1-2, pp. 109-120 (in Russian).

13. Pervyy shag: ot avtoritarizma k avtorstvu: ucheb.-metod. materialy k obrazovatel'noy programme "Pedagog - uchastnik i organizator sovmestnoy deyatel'nosti" [The first step: from authoritarianism to authorship: Educational materials for the educational program "The teacher is a participant and organizer of joint activities"]. Tomsk, TSPU Publ., 2001. Pp. 10-14 (in Russian).

Kovalevskaya E. N., Tomsk State Pedagogical University (ul. Kiyevskaya, 60, Tomsk, Russian Federation, 634061). E-mail: iff2001@yandex.ru

Kuryanovich A. V., Tomsk State Pedagogical University (ul. Kiyevskaya, 60, Tomsk, Russian Federation, 634061). E-mail: anna.kurjanowitch@yandex.ru

Dukmas A. I., Secondary school № 14 named after A. F. Lebedeva (ul. Karla Ilmera, 11, Tomsk, Russian Federation, 634057). E-mail: nastya261092@yandex.ru 